\title{
STANDARDISATION OF THE NITROBLUE-TETRAZOLIUM TEST
}

\author{
D. Merzbach AND Nora Obedeanu \\ Department of Microbiology, Rambam University Hospital and \\ Technion Aba Khoushy School of Medicine, Haifa, Israel
}

THE supravital nitroblue-tetrazolium (NBT)-reduction test was introduced by Park, Fikrig and Smithwick (1968) with the aim of detecting bacterial infections in patients with fever of unknown origin. This test is based on experimental observations showing that in normal, healthy individuals, as well as in patients with non-bacterial diseases, only small proportions of peripheral blood phagocytes spontaneously reduce pale yellow NBT dye to dark purple formazan. On the other hand, a high percentage of NBT-reducing cells was observed in patients with systemic bacterial infections, in which phagocytosis occurs, a process that triggers the liberation of granular enzymes in more phagocytes.

The test has been comprehensively reviewed in the literature (Feigin, 1971; Lancet, 1971; Matula and Paterson, 1971a; Park, 1971; Tadmor and Altmann, 1971; Miescher and Lambert, 1972); critical and controversial opinions about it (Freeman and King, 1972a; Björksten and Solheim, 1973; Matula and Raas, 1973; Sobel et al., 1973) stem from the recording of inconsistent values in various diseases and from difficulties in establishing the upper limit of normal. This variability might be attributed, among other things, to lack of uniform testing conditions, a factor of utmost importance in a supravital reduction process.

It is the purpose of this study to examine various technical details in the performance of the standard and stimulated NBT tests.

\section{MATERIALS AND METHODS}

Patients. Blood specimens were collected at random from in-patients in the Department of Internal Medicine A, Rambam University Hospital, Haifa. All were adults suffering from diseases such as myocardial infarction or other heart conditions, diabetes, colitis, hypertension, infectious and non-infectious hepatitis, malignancies, peptic ulcer and pulmonary conditions.

Blood collection for the standard NBT test. Plastic utensils or siliconised glassware were used throughout the procedure. Samples of venous blood, $2 \mathrm{ml}$ in volume, were taken into vials containing 40 units of heparin (0.008 ml of Pullarin, Evans Medical Ltd, Liverpool) and mixed well.

Standard NBT-reduction procedure. Unless otherwise stated, tests were performed within 15 min. of blood collection. In a small capped plastic cup (as used with the Autoanalyzer apparatus, Technicon Instruments Corp., Chauncey, NY), $0.1 \mathrm{ml}$ of whole blood and $0.1 \mathrm{ml}$ of a $0.1 \%$ NBT solution were mixed. The cup was placed for $15 \mathrm{~min}$. in a $37^{\circ} \mathrm{C}$ air incubator; after mixing, the fluid remained for another $10 \mathrm{~min}$. at room temperature. Smears were then made on xylol-cleaned glass slides and air-dried; they were fixed with May-Grünwald solution, Giemsa-stained and examined microscopically with the oilimmersion lens. The number of NBT-positive leucocytes among 100 consecutive polymorphonuclear (PMN) neutrophilic leucocytes-the NBT index-was recorded as a percentage. NBT positivity was considered to be characterised by a massive or granular, dark purple or black precipitate, within the leucocytes. Dark hues, diffusely distributed throughout the cell cytoplasm, were not taken into account. If possible, only isolated and intact PMN leucocytes were counted.

Alterations to the method of the standard NBT-reduction test are described in the text.

NBT solution. The $0 \cdot 1 \%$ and $0.2 \%$ NBT solutions, used respectively in the standard and

Received 26 Feb. 1974; revised version accepted 12 Sept. 1974.

J. MED. MICROBIOL.-VOL. 8 (1975) 
stimulated tests, were prepared by dissolving NBT (Sigma Laboratories, Grade III) in

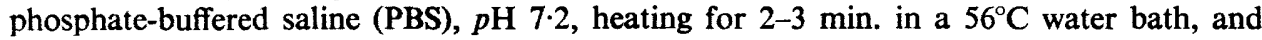
filtering through $0.22-\mu \mathrm{m}$ Millipore filters. These solutions were kept in amber glass bottles at $4^{\circ} \mathrm{C}$.

The hydrogen-accepting capacity of the NBT solutions was tested before use with an alkaline solution of ascorbic acid.

Endotoxin solutions. For the endotoxin-stimulated tests, Bacto-Lipopolysaccharides Boivin (Difco Laboratories, Detroit, Mich.) were used. Solutions were prepared by dissolving the necessary amount of lipopolysaccharide in PBS, $p H \mathbf{H} \cdot \mathbf{2}$. Varying concentrations of

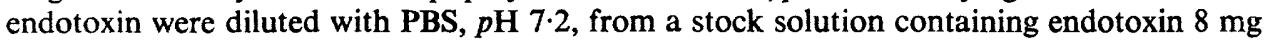
per $\mathrm{ml}$.

Endotoxin solutions were kept at $-20^{\circ} \mathrm{C}$ and thawed before use. Thawed solutions were discarded after use.

\section{RESULTS}

Effect of heparin. Ten venous-blood samples were distributed in vials containing heparin to achieve final concentrations of 20,50, 100, and 200 units per $\mathrm{ml}$ of blood. All had NBT indices of less than $10 \%$ in the standard test (i.e. with heparin 20 units per $\mathrm{ml}$ ). The results presented in table I show an increase of the NBT index at higher concentrations of heparin, up to 100 units per $\mathrm{ml}$. Some, but by no means all, of these increases took the result above the generally accepted upper limit of normal for the test (an index of $10 \%$ ). On the other hand, an anticoagulant concentration of 200 units per $\mathrm{ml}$ resulted in an NBT index very close to that recorded with 20 units per $\mathrm{ml}$.

Effect of delay in test performance. NBT tests were performed according to the standard method on 10 blood samples, at various times after blood collection, as follows: within $15 \mathrm{~min}$, at 2,4 , and $24 \mathrm{~h}$ at room temperature, and at $24 \mathrm{~h}$ at $4^{\circ} \mathrm{C}$; all had indices of less than $10 \%$ when first tested. Table II and the figure show that there was practically no difference between the results of tests performed at $15 \mathrm{~min}$. and at $2 \mathrm{~h}$. In some normal, uninfected patients, higher NBT scores were recorded the longer the blood was kept at room temperature, and eventually the scores exceeded the normal range. Except for one case, all NBT indices determined in samples kept for $24 \mathrm{~h}$ at $4^{\circ} \mathrm{C}$ were below the upper limit of normal. The longer the blood was left at room temperature, the more the leucocytes tended to lose their integrity and become clumped; consequently, counting became more difficult and less accurate. Most of these shortcomings were overcome by keeping the blood at $4^{\circ} \mathrm{C}$, even for as long as $24 \mathrm{~h}$.

Effect of composition of the NBT reagent. Standard NBT-reduction tests were performed on 17 blood samples by incubating portions of the same specimen with each of the NBTreagent solutions described in table III. Results were compared with those obtained with the reagent used in the standard test (solution no. 10). The addition of glucose to the incubation mixture did not significantly change the NBT scores (solution no. 1 versus solution no. 2,

TABLE I

Effect of heparin on nitroblue-tetrazolium (NBT) indices

\begin{tabular}{cccc}
\hline \multicolumn{3}{c}{$\begin{array}{c}\text { NBT index }(\%)^{*} \pm 1 \text { SD (and range) in tests with a } \\
\text { heparin concentration (units per ml) of }\end{array}$} \\
\hline 20 & 50 & 100 & 200 \\
\hline $\begin{array}{c}3 \cdot 7 \pm 2 \cdot 5 \\
(1-8)\end{array}$ & $\begin{array}{c}6 \cdot 8 \pm 3 \cdot 3 \\
(2-12)\end{array}$ & $\begin{array}{c}8 \cdot 3 \pm 4 \cdot 0 \\
(3-14)\end{array}$ & $\begin{array}{c}3 \cdot 6 \pm 3 \cdot 1 \\
(0-9)\end{array}$ \\
\hline
\end{tabular}

* Averages of 10 blood specimens. 
and solution no. 7 versus solution no. 10). The veronal buffer (solutions nos. 1 and 2) appeared to induce lower reduction indices, showing four out of 17 false-negative results as compared with the standard test. Hanks' balanced salt solution (HBSS) produced slightly higher indices. Blood mixtures containing this buffer (solution no. 3) showed a marked tendency to clot when standing at room temperature before preparation of the smears.

Variation in the $p \mathrm{H}$ of PBS affected NBT scores more markedly in an acid environment.

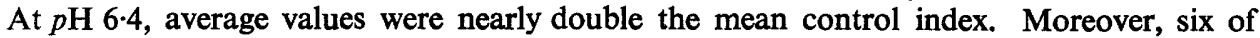
17 results were "false positives" as compared with the control reagent, while the PMN leucocytes showed visible signs of deterioration, such as spilling of cell contents outside the

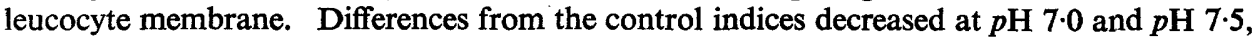
but average NBT indices remained higher than those of the control; false-positive and even false-negative tests were found, though to a lesser extent-two cases out of 17 at $p \mathbf{H ~ 7 . 5}$. Much leucocyte clumping was seen at all these $p \mathrm{H}$ values, while $p \mathrm{H} 6.4$ apparently had the most damaging effect upon cells, as was ascertained microscopically.

When the dye concentration in the incubation mixture was doubled (solution no. 9), somewhat higher results were recorded, with one false-positive result in 17 samples; the leucocytes were also distorted and clumped. When the concentration was halved (solution no. 8), cell clumping and damaged phagocytes were not seen, and NBT indices were consistently lower than in the control. Moreover, with all six samples with raised NBT indices in the standard test, this diluted reagent gave low indices, i.e. less than $10 \%$.

Stimulated NBT test. Park and Good (1970) devised a NBT test stimulated by bacterial products. This test enabled them to differentiate low NBT indices in healthy individuals from decreased NBT indices due to some defect of the cellular or humoral systems in infected patients. Similar tests have been described, with varying technical details, by Matula and Paterson (1971a), Anner et al. (1972), Chretien and Garagusi (1972), Freeman and King (1972b), Nydegger et al. (1973), and Rubinstein and Pelet (1973). In an attempt to standardise the stimulated test, various conditions of test performance were assayed as follows:

(a) Incubation. Nineteen $0.1 \mathrm{ml}$ portions of whole-blood specimens containing heparin 20 units per $\mathrm{ml}$ were mixed with $0.05 \mathrm{ml}$ of Escherichia coli 055 : B5 lipopolysaccharide solution, resulting in a final endotoxin concentration of $40 \mu \mathrm{g}$ per ml. Parallel similar mixtures were incubated for $15 \mathrm{~min}$. at room temperature and for 15 and $30 \mathrm{~min}$. in a $37^{\circ} \mathrm{C}$ water bath. Then $0.05 \mathrm{ml}$ of a $0.2 \%$ NBT solution was added and the mixtures were incubated for another $15 \mathrm{~min}$. in a $37^{\circ} \mathrm{C}$ air incubator. Smears were made immediately, because preliminary tests showed a tendency of these mixtures to clot rather quickly upon standing at room temperature. The results obtained after a $15-\mathrm{min}$. incubation period at $37^{\circ} \mathrm{C}$ were much higher than those recorded after incubation at room temperature (table IV). Doubling the incubation period at $37^{\circ} \mathrm{C}$ did not significantly change the results. It was therefore decided to adopt an incubation procedure of $15 \mathrm{~min}$. at $37^{\circ} \mathrm{C}$ for subsequent stimulated tests.

(b) Optimal concentration of endotoxin. Assays were performed with E. coli O55 : B5

TABLE II

Effect of delay in performance of the test

\begin{tabular}{ccccc}
\hline \multicolumn{5}{c}{$\begin{array}{c}\text { NBT index }(\%)^{*} \pm 1 \text { SD (and range) at the indicated time and } \\
\text { temperature after the collection of blood }\end{array}$} \\
\hline $\begin{array}{ccccc}15 \mathrm{~min} . \\
\mathrm{RT}\end{array}$ & $\begin{array}{c}2 . \mathrm{h} \\
\mathrm{RT}\end{array}$ & $\begin{array}{c}4 \mathrm{~h} \\
\mathrm{RT}\end{array}$ & $\begin{array}{c}24 \mathrm{~h} \\
\mathrm{RT}\end{array}$ & $\begin{array}{c}24 \mathrm{~h} \\
4^{\circ} \mathrm{C}\end{array}$ \\
\hline $\begin{array}{c}3 \cdot 0 \pm 2 \cdot 6 \\
(0-8)\end{array}$ & $\begin{array}{c}2 \cdot 5 \pm 2 \cdot 2 \\
(0-8)\end{array}$ & $\begin{array}{c}5 \cdot 4 \pm 4 \cdot 2 \\
(0-14)\end{array}$ & $\begin{array}{c}10 \cdot 0 \pm 8 \cdot 7 \\
(1-25)\end{array}$ & $\begin{array}{c}2 \cdot 9 \pm 2 \cdot 3 \\
(1-16)\end{array}$ \\
\hline
\end{tabular}

$\mathrm{RT}=$ room temperature

* Averages of 10 blood specimens. 


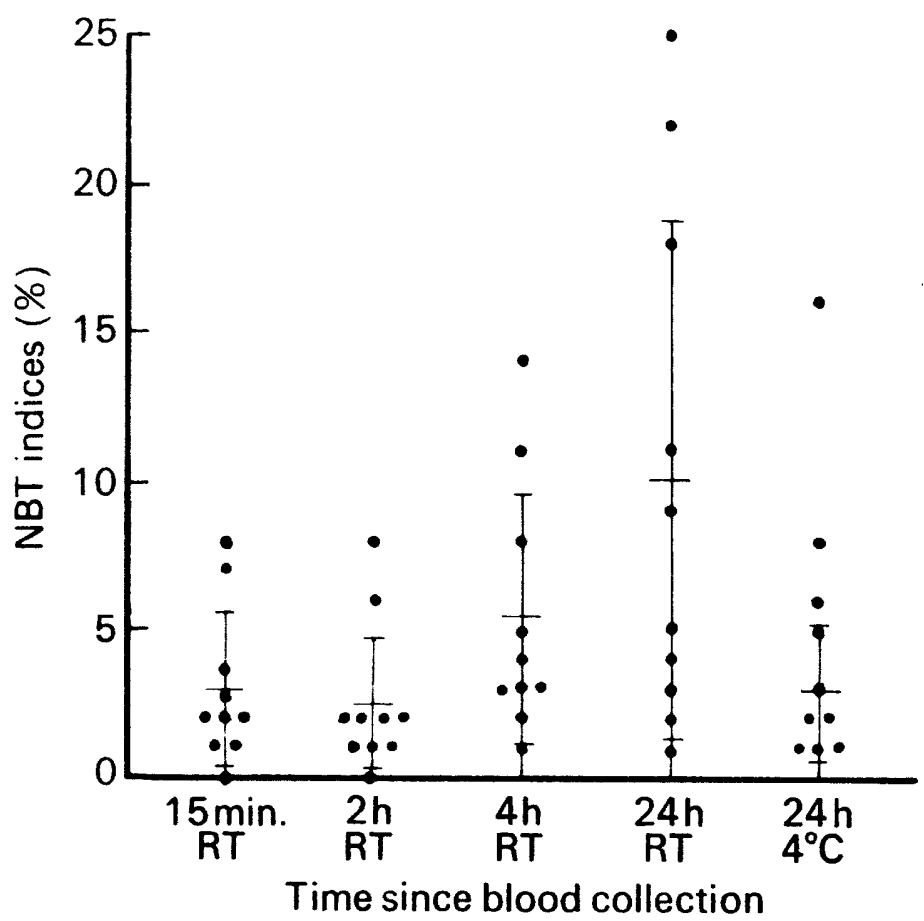

FIGURE-Individual NBT indices recorded for 10 blood specimens at various time-intervals after collection, and storage at room temperature (RT) and at $4^{\circ} \mathrm{C}$. The mean and one standard deviation of the mean are given for each group of values. $\mathrm{RT}=$ room temperature.

TABLE III

Effect of composition of NBT-reagent solutions on the NBT index

\begin{tabular}{|c|c|c|c|c|c|}
\hline $\begin{array}{l}\text { Solution } \\
\text { number }\end{array}$ & Buffer & $p \mathrm{H}$ & $\begin{array}{c}\text { Glucose } \\
\text { concentration } \\
(\%)\end{array}$ & $\begin{array}{c}\text { NBT } \\
\text { concentration } \\
(\%)\end{array}$ & $\begin{array}{c}\text { NBT index }(\%)^{*} \pm 1 \text { SD } \\
\text { (and range) }\end{array}$ \\
\hline $\begin{array}{r}1 \\
2 \\
3 \\
4 \\
5 \\
6 \\
7 \\
8 \\
9 \\
10\end{array}$ & $\begin{array}{l}\text { Veronal } \\
\text { Veronal } \\
\text { HBSS } \\
\text { PBS } \\
\text { PBS } \\
\text { PBS } \\
\text { PBS } \\
\text { PBS } \\
\text { PBS } \\
\text { PBS }\end{array}$ & $\begin{array}{l}7 \cdot 2 \\
7 \cdot 2 \\
7 \cdot 2 \\
6 \cdot 4 \\
7 \cdot 0 \\
7 \cdot 5 \\
7 \cdot 2 \\
7 \cdot 2 \\
7 \cdot 2 \\
7 \cdot 2\end{array}$ & $\begin{array}{l}\overline{0 \cdot 1} \\
= \\
\bar{z} \\
\overline{0 \cdot 1} \\
=\end{array}$ & $\begin{array}{l}0 \cdot 1 \\
0 \cdot 1 \\
0 \cdot 1 \\
0 \cdot 1 \\
0 \cdot 1 \\
0 \cdot 1 \\
0 \cdot 1 \\
0 \cdot 05 \\
0 \cdot 2 \\
0.1\end{array}$ & $\begin{array}{r}6 \cdot 8 \pm 6 \cdot 1(0-22) \\
7 \cdot 0 \pm 5 \cdot 6(1-19) \\
8 \cdot 5 \pm 7 \cdot 0(0-23) \\
15 \cdot 8 \pm 8 \cdot 3(6-40) \\
12 \cdot 9 \pm 8 \cdot 4(4-34) \\
11 \cdot 9 \pm 7 \cdot 4(1-30) \\
8 \cdot 0 \pm 6 \cdot 8(1-22) \\
3 \cdot 3 \pm 3 \cdot 0(0-9) \\
11 \cdot 5 \pm 9 \cdot 7(1-33) \\
8 \cdot 1 \pm 6 \cdot 5(2-19)\end{array}$ \\
\hline
\end{tabular}

FIBSS $=$ Hanks' balanced salt solution; PBS $=$ Phosphate-buffered saline.

* Average of results on 17 blood specimens. 
lipopolysaccharide in tenfold increments of concentration ranging from $0.02 \mu \mathrm{g}$ to $2000 \mu \mathrm{g}$ perml of blood. Results recorded in 11 blood specimens are illustrated in table V. They show that, beyond $20 \mu \mathrm{g}$ endotoxin per $\mathrm{ml}$ of blood, there was little increase in the leucocyte response to the stimulant. A concentration of $20 \mu \mathrm{g}$ endotoxin per $\mathrm{ml}$ of blood was therefore chosen for subsequent work.

(c) Type of lipopolysaccharide. The effect of various types of lipopolysaccharides on the NBT response was examined by incubating each of 11 blood samples with the following lipopolysaccharides, $20 \mu \mathrm{g}$ per $\mathrm{ml}$ of blood: E. coli $\mathrm{O} 111$ : B4, E. coli $\mathrm{O} 26: \mathrm{B} 6$, E. coli 0127 : B8, E. coli O55 : B5, Salmonella typhimurium, Salm. typhi, Salm. enteritidis, Shigella flexneri, and Serratia marcescens. The NBT indices recorded in stimulated tests with all of the endotoxins tested (table VI) were at least twice the unstimulated NBT score and very often much more (range $43-49.9 \%$ ). The average values induced by individual lipopolysaccharides were very similar, with the exception of $E$. coli 055 : B5 endotoxin, which inexplicably resulted in a lower stimulated index (average $35.4 \%$ ) of NBT reduction.

Table VII presents the average results of these 11 individual blood specimens when tested with all nine endotoxins. The average values for these specimens show a high degree of variability; the lowest average was $19 \cdot 1 \pm 7.8 \%$ and the highest $73.3 \pm 6.0 \%$. The standard deviations were, however, lower than those given in table VI, indicating a similar response of one individual sample to all nine endotoxins tested.

In one patient receiving heparin therapy, a very low average of $6.0 \pm 3.3 \%$ was obtained as a response to the nine endotoxins. This specimen was excluded from these experiments.

\section{Discussion}

Effect of anticoagulant. It is recommended (Farnes et al., 1972; Björksten and Solheim, 1973) that the heparin concentration be limited to 10 or 20 units per ml blood, because higher NBT indices may be induced by increasing the heparin concentration. On the other hand, the effect of heparin on the NBT-reducing capacity of a washed neutrophil suspension is considerably diminished in the presence of autologous serum (Nydegger et al., 1973). Other authors (Park and Good, 1970; Freeman and King, 1972b) have also pointed out the effect of plasma factors in this test, and Baehner (1972) specifically warned against comparing results of tests with washed suspensions of leucocytes with data obtained when the natural proportions of humoral and cellular blood components were maintained. Recently, Segal and Levi (1973) showed that heparin or fibrinogen, or both, are essential for the process of dye reduction. The presence of plasma factors is even more important in tests on patients with bacterial infection and underlying diseases such as diabetes (de la Vega, Freyre-Horta and Benitez-Bibriesca, 1973; Pujol-Moix, 1973), or systemic lupus erythematosus (Wenger and Bole, 1973). It follows that the NBT indices have to be regarded with great caution if

TABLE IV

Effect of conditions of incubation on stimulated NBT tests

\begin{tabular}{|c|c|c|c|}
\hline \multicolumn{4}{|c|}{ NBT index $(\%)^{*} \pm 1$ SD (and range) under the indicated conditions } \\
\hline \multirow{2}{*}{$\underset{\text { test }}{\text { Standard }}$} & \multicolumn{3}{|c|}{ Incubation with endotoxin $\uparrow$ for } \\
\hline & 15 min. at $\mathrm{RT}$ & 15 min. at $37^{\circ} \mathrm{C}$ & $30 \mathrm{~min}$. at $37^{\circ} \mathrm{C}$ \\
\hline $\begin{array}{c}4 \cdot 2 \pm 3 \cdot 1 \\
(0-10)\end{array}$ & $\begin{array}{c}19 \cdot 9 \pm 12 \cdot 9 \\
(3-50)\end{array}$ & $\begin{array}{c}31 \cdot 2 \pm 12 \cdot 0 \\
(11-54)\end{array}$ & $\begin{array}{c}32 \cdot 9 \pm 8 \cdot 5 \\
(10-51)\end{array}$ \\
\hline
\end{tabular}

* Averages of 19 blood specimens.

$\dagger$ Stimulation with Escherichia coli 055 : B5 endotoxin $40 \mu \mathrm{g}$ per ml. $\mathbf{R T}=$ Room temperature. 
TABLE V

Effect of increasing endotoxin concentrations on stimulated NBT indices

\begin{tabular}{|c|c|c|c|c|c|c|}
\hline \multicolumn{7}{|c|}{ Stimulated NBT index $(\%)^{*} \pm 1$ SD (and range) with endotoxin $\dagger$ concentration ( $\mu \mathrm{g}$ per ml) of } \\
\hline 0 & 0.02 & 0.2 & $2 \cdot 0$ & 20 & 200 & 2000 \\
\hline $\begin{array}{c}5 \cdot 0 \pm 2 \cdot 9 \\
(2-10)\end{array}$ & $\begin{array}{c}13 \cdot 5 \pm 10 \cdot 5 \\
(5-35)\end{array}$ & $\begin{array}{c}18 \cdot 5 \pm 9 \cdot 2 \\
(5-30)\end{array}$ & $\begin{array}{c}19 \cdot 3 \pm 9 \cdot 9 \\
(4-37)\end{array}$ & $\begin{array}{c}26 \cdot 6 \pm 11 \cdot 5 \\
(10-48)\end{array}$ & $\begin{array}{c}22 \cdot 7 \pm 8 \cdot 0 \\
(11-38)\end{array}$ & $\begin{array}{c}25 \cdot 1 \pm 13 \cdot 3 \\
(8-49)\end{array}$ \\
\hline
\end{tabular}

heparin is replaced by sequestrene alone (Nydegger et al., 1973) or together with Ficoll sucrose polymer (Gordon et al., 1973), or if anticoagulants are omitted (Vaucher et al., 1970). Such variations in technique, besides complicating an otherwise simple procedure, also modify the natural proportion of extracellular factors, thus influencing the results to an unknown extent.

Our results demonstrate that higher heparin concentrations cause an increase in NBT score. The effect of heparin was, however, of variable magnitude, with fairly large deviations from the mean value, most NBT indices remaining within the upper limit of normal. The serum factors present in the whole-blood mixtures may possibly account for this apparently attenuated effect of heparin. On the other hand, with very high concentrations of heparin, e.g., 200 units per $\mathrm{ml}$, the NBT indices were lower and comparable with the values obtained with a heparin concentration of 20 units per $\mathrm{ml}$. This observation suggests a possible inhibitory effect of very high heparin concentrations on the capacity of the leucocytes to reduce the dye, and is in conformity with the fact that stimulated NBT scores were consistently low in a patient receiving large amounts of heparin for the treatment of pulmonary infarction.

In our opinion, a heparin concentration of 20 units per $\mathrm{ml}$ of blood, and not more, should be used as anticoagulant for blood collected for NBT tests.

Effect of delay in performance of the test. Most authors agree that the test should be performed as soon as possible after blood collection, preferably within $30 \mathrm{~min}$. (Humbert et al., 1971) or at most within 1 to $2 \mathrm{~h}$ (Feigin et al., 1971). If a longer delay is unavoidable, the storage of blood samples at $4^{\circ} \mathrm{C}$ has been recommended (Gordon et al., 1973; Nydegger et al., 1973). Some false-positive results have been ascribed to keeping the blood for a longer time at room temperature (Björksten and Solheim, 1973). We confirmed the above statements in part, and observed that increases in the NBT index that eventually exceed the upper limit of normal may occur in uninfected patients whose blood is kept at room temperature. The fact that one in 10 of our samples yielded an abnormal result after being kept for $24 \mathrm{~h}$ at $4^{\circ} \mathrm{C}$ points to the importance of performing the test immediately after blood collection.

\section{TABLE VI}

Effect of various types of endotoxins on stimulated NBT indices

\begin{tabular}{|c|c|c|c|c|c|c|c|c|c|}
\hline \multicolumn{10}{|c|}{ NBT index $(\%)^{*} \pm 1$ SD (and range) } \\
\hline \multicolumn{9}{|c|}{ in stimulated test with endotoxin of } & \multirow{2}{*}{$\underset{\substack{\text { in } \\
\text { test }}}{\text { unstimulated }}$} \\
\hline E. coli $\mathrm{B} 4111:$ & E. coli ${ }_{\mathrm{B} 6} \mathrm{O26}$ & $\begin{array}{l}\text { E. coli O127: } \\
\mathbf{B 8}\end{array}$ & $E . \underset{\mathrm{BS}}{\operatorname{coli}} \mathrm{O55}$ & $\underset{\text { typhimurium }}{\text { Salmonella }}$ & $\underset{\text { typhi }}{\text { Salm. }}$ & $\begin{array}{c}\text { Salm. } \\
\text { enteritidis }\end{array}$ & $\begin{array}{l}\text { Shigella } \\
\text { flexneri }\end{array}$ & $\begin{array}{c}\text { Serratia } \\
\text { marcescens }\end{array}$ & \\
\hline $\begin{array}{c}47 \cdot 6 \pm 20 \cdot 0 \\
(19-80)\end{array}$ & $\begin{array}{c}48 \cdot 0 \pm 16 \cdot 9 \\
(19-78)\end{array}$ & $\begin{array}{c}47 \cdot 4 \pm 18.9 \\
(10-70)\end{array}$ & $\begin{array}{c}35 \cdot 4 \pm 15 \cdot 4 \\
(16-63)\end{array}$ & $\begin{array}{c}44 \cdot 0 \pm 23 \cdot 7 \\
(10-78)\end{array}$ & $\begin{array}{c}49 \cdot 0 \pm 21 \cdot 3 \\
(16-78)\end{array}$ & $\begin{array}{c}43 \cdot 0 \pm 19 \cdot 7 \\
(12-79)\end{array}$ & $\begin{array}{c}49 \cdot 9 \pm 19 \cdot 0 \\
(23-80)\end{array}$ & $\begin{array}{c}43 \cdot 0 \pm 18 \cdot 7 \\
(17-83)\end{array}$ & $\begin{array}{c}5 \cdot 2+4 \cdot 9 \\
0-16\end{array}$ \\
\hline
\end{tabular}

* Averages of 11 blood specimens.

+ Stimulation with each type of endotoxin $20 \mu \mathrm{g}$ per ml of blood. 
Consequently, it is advisable to perform the test at most within $90 \mathrm{~min}$. of blood collection. If a longer delay is unavoidable, specimens should be stored at $4^{\circ} \mathrm{C}$, and for no more than $6 \mathrm{~h}$.

Effect of the composition of the reagent. The constituents incorporated in the NBT reagent, the only components of external source in the test, should also be accurately standardised. Park et al. (1968) recommended a mixture of equal amounts of $0.2 \%$ NBT in physiological saline and $0.15 \mathrm{M}$ PBS, $p \mathrm{H} \mathrm{7.2}$, with a final dye concentration in the incubation mixture of $0.05 \%$. Krebs-Ringer phosphate buffer, $p \mathrm{H} 7 \cdot 4$, containing $0.1 \%$ of glucose

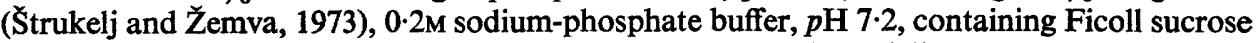
polymer $200 \mathrm{mg}$ per $\mathrm{ml}$ (Gordon et al., 1973), and HBSS (Mandell and Fuller, 1972) have also been used as buffers.

In this study, negligible differences in NBT indices were observed in media with or without glucose. Hence, additional glucose as a source of energy is not necessary for phagocytosis. Various buffers, though leading to results similar to those obtained with PBS, often produce undesirable side effects, such as blood clotting induced by HBSS. Moreover, changes in $p \mathrm{H}$ of the buffers seem to cause clumping of leucocytes. An acid environment induces more destructive effects, such as clumping associated with spilling of leucocyte contents. In these damaged leucocytes, granular reducing enzymes are probably liberated, and massive precipitates of formazan are present. Consequently, accurate recording of the NBT index is difficult, and this results in false-positive results.

Final NBT-dye concentrations of $0.05 \%, 0.025 \%$, and $0.1 \%$ have been used (Park et al., 1968; Humbert et al., 1971; Gordon et al., 1973). Gifford and Malawista (1972) observed a somewhat toxic effect with a $0.12 \%$ of NBT in their stimulated tests, but not with the usual concentration of $0.05 \%$. We saw similar toxic phenomena in the standard test, with a final NBT concentration of $0.1 \%$; clumping and leucocyte deterioration were frequent and, as a result, high NBT indices were scored. On the other hand, a final dye concentration of $0.025 \%$ led to significantly lower indices, and leucocyte integrity was well preserved. Obviously, such a low dye concentration is insufficient for the supravital reduction.

It is our opinion that a $0 \cdot 1 \% \mathrm{NBT}$ solution in $\mathrm{PBS}, p \mathrm{H} 7 \cdot 2$, giving a final dye concentration of $0.05 \%$ in the incubation mixture, should be used in the standard test.

Effect of temperature. Baehner and Nathan (1968) using a quantitative method, advocated an optimal temperature of $37^{\circ} \mathrm{C}$ for NBT reduction by PMN leucocytes; the same temperature conditions should also apply to the supravital technique. Incubation for $15 \mathrm{~min}$. (Park et al., 1968), $25 \mathrm{~min}$. (Matula and Paterson, 1971a), $30 \mathrm{~min}$. (Humbert et al., 1971; Wenger and Bole, 1973) and even $60 \mathrm{~min}$. (Chretien and Garagusi, 1972) has been suggested, in an air incubator or a water bath (Humbert et al., 1971). However, the time required to attain a temperature of $37^{\circ} \mathrm{C}$ in the blood mixture varies within wide limits, depending mainly on the heating procedure, i.e. water bath, air incubator, or thermal block (Charette and Komp, 1972). As a result, NBT scores obtained with different incubation methods varied and are therefore not comparable.

It is highly advisable to use strictly standardised incubation conditions, namely those recommended by the authors of this method, $15 \mathrm{~min}$. and $37^{\circ} \mathrm{C}$, in an air incubator.

The stimulated NBT test. The reliability of the NBT test requires normal functioning of the humoral and cellular phagocytic systems in the host (Park, 1971). Decreased NBT

TABLE VII

Effect of nine different endotoxins on individual stimulated NBT indices

\begin{tabular}{|c|c|c|c|c|c|c|c|c|c|c|}
\hline \multicolumn{11}{|c|}{ Stimulated NBT index $(\%)^{*} \pm 1$ SD (and range) in tests on blood sample number } \\
\hline 1 & 2 & 3 & 4 & 5 & 6 & 7 & 8 & 9 & 10 & 11 \\
\hline $\begin{array}{c}34 \cdot 0 \pm 7 \cdot 7 \\
(21-44)\end{array}$ & $\begin{array}{c}48 \cdot 0 \pm 6 \cdot 7 \\
(36-55)\end{array}$ & $\begin{array}{c}19 \cdot 1 \pm 7 \cdot 8 \\
(10-35)\end{array}$ & $\begin{array}{c}40 \cdot 0 \pm 9 \cdot 5 \\
(28-61)\end{array}$ & $\begin{array}{c}44 \cdot 2 \pm 9 \cdot 6 \\
(33-58)\end{array}$ & $\begin{array}{c}21 \cdot 0 \pm 5 \cdot 7 \\
(12-31)\end{array}$ & $\begin{array}{c}71 \cdot 5 \pm 9 \cdot 8 \\
(51-80)\end{array}$ & $\begin{array}{c}52 \cdot 3 \pm 13 \cdot 5 \\
(30-79)\end{array}$ & $\begin{array}{c}60 \cdot 4 \pm 10 \cdot 8 \\
(44-83)\end{array}$ & $\begin{array}{c}42 \cdot 6 \pm 8 \cdot 8 \\
(21-61)\end{array}$ & $\begin{array}{c}73 \cdot 3 \pm 60 \\
(63-80)\end{array}$ \\
\hline
\end{tabular}

* Average of nine tests on the same blood sample, each with a different endotoxin $20 \mu \mathrm{g}$ per $\mathrm{ml}$ of blood. 
responses have been unexpectedly recorded in patients with a systemic bacterial infection and (1) certain haematological disorders (Feigin et al., 1971 ; Lancet, 1971 ; Tan, Rosner and Feldman, 1973) or (2) under intensive drug therapy with antibiotics (Rubinstein and Pelet, 1973) or corticosteroids (Matula and Paterson, 1971b; Chretien and Garagusi, 1972; Freeman, King and Kite, 1973).

The stimulated test was devised by Park and Good (1970) to overcome this drawback. The blood was incubated with certain bacterial products before performing the NBT test. Under these conditions, normal leucocytes reduced the dye more actively, attaining reduction levels similar to those obtained in cases of bacterial infection. When the phagocytic function was impaired, abnormally low increases were observed, which eventually did not exceed normal limits. Even more, in chronic granulomatous disease of childhood, although stimulated, the NBT-test score remained zero. Such information could be of utmost importance in clinical investigations.

Various procedures have been used for the stimulated NBT test (Park and Good, 1970; Chretien and Garagusi, 1972; Freeman and King, 1972b; Gifford and Malawista, 1972; Rubinstein and Pelet, 1973). Methods of stimulation included: simple leucocyte adhesion to a glass surface (Gifford and Malawista, 1972); addition of purified bacterial endotoxins (Park and Good, 1970; Matula and Paterson, 1971 $a$ and $b$; Freeman and King, 1972b; Nydegger et al., 1973); addition of either bacterial broth-culture filtrates (Matula and Paterson, 1971a) or of particulate matter such as latex (Chretien and Garagusi, 1972) and live or heat-killed bacterial suspensions (Anner et al., 1972; Rubinstein and Pelet, 1973).

In the present study an attempt was made to establish optimal conditions for the stimulated test. Lyophilised lipopolysaccharides were chosen as stimulants; these soluble products are suitable for the preparation of accurately standardised solutions, and, if kept in a frozen state, are fairly stable for at least 3 months. High dilutions of these endotoxins can be easily prepared.

On the basis of our experiments, the following procedure is suggested: separate incubation of blood specimens with endotoxin $20 \mu \mathrm{g}$ per ml of blood, for $15 \mathrm{~min}$. in a $37^{\circ} \mathrm{C}$ water bath, followed by the standard NBT test. With this procedure, significant increases in the reduction values were obtained in the stimulated (mean $45.2 \%$ ) as compared with the standard, unstimulated test (mean $5 \cdot 2 \%$ ).

Matula and Paterson (1971a) reported a high variability in different blood samples of the leucocyte response to bacterial products. This observation was confirmed in our study. However, the variability of individual blood responses to various bacterial products (Matula and Paterson, 1971a) could not be confirmed. With the exception of E. coli O55 : B5 endotoxin, all eight other endotoxins tested resulted in similar average NBT scores, with relatively low standard deviations in the same blood specimen.

In 11 of 12 blood specimens, a clear-cut stimulating effect could be found. With all endotoxins tested, a very low stimulation of $3-13 \%$ as compared with a standard NBT index of $1 \%$ was noted in only one case. This specimen was obtained from a pregnant woman with a pulmonary infarction, treated with large quantities of heparin at the time of the test performance. This case illustrates the importance of investigating more closely the effect of similar therapies on PMN leucocyte reactions, as well as the need to take into account all clinical details when interpreting NBT test results.

Finally, it is strongly suggested that NBT reduction should generally be determined by using the standard and the stimulated procedures. The parallel results thus obtained enable the disclosure of a variety of abnormal neutrophil responses due either to some natural intrinsic cause, or to various drugs in current clinical use.

\section{SUMMARY}

Optimal conditions for the NBT-reduction test have been sought. Increasing heparin concentrations up to 100 units per $\mathrm{ml}$ and a delay in performance of the test, especially when blood specimens are kept at room temperature, resulted in higher values for the NBT index, which then sometimes exceeded the upper limit of normal in healthy people and in uninfected 
patients. The effect of $p \mathrm{H}$, composition of the buffer, and dye concentration was also investigated. Phosphate-buffered saline $p \mathrm{H} 7 \cdot 2$ containing $0.1 \%$ NBT dye, without glucose, gave the most reliable results.

In endotoxin-stimulated NBT tests, the following procedure is recommended: incubation of $0.1 \mathrm{ml}$ whole blood with lyophilised endotoxin $20 \mu \mathrm{g}$ per ml, for $15 \mathrm{~min}$. in a $37^{\circ} \mathrm{C}$ water bath, followed by the standard test with a $0.2 \%$ NBT solution. By this technique, the leucocyte reaction to various types of lipopolysaccharides was of the same order of magnitude. Drug therapy having an effect on blood components lowered this reaction, whatever the source of endotoxin used as stimulant.

The importance of NBT-reduction tests is discussed. Standard conditions of test performance are strictly requisite if comparable results are to be obtained and if data not corresponding with the apparent clinical and other laboratory findings are to be evaluated correctly. The stimulated NBT test, performed in parallel with the standard test, is useful in the interpretation of abnormal results and in the detection of factors with a temporary or permanent effect on the phagocytic activity of PMN leucocytes.

We thank the medical staff of the Department of Internal Medicine A, Rambam University Hospital, for allowing us to study patients under their care. The assistance of Dr G. Brook in reviewing this manuscript is gratefully acknowledged.

\section{REFERENCES}

ANNer, R. M., Nydegger, U. E., Schmocker, K., LAmbert, P. H. AND Miescher, P. A. 1972. Etude expérimentale et clinique du test au NBT. Schweiz. med. Wschr, 102, 1606.

BAfHNER, R. L. 1972. Conflicting results in metabolic studies of leukocytes from patients with osteogenesis imperfecta. Notes on NBT test. J. Pediat., 80, 346.

BAEHNER, R. L. AND NATHAN, D. G. 1968. Quantitative nitroblue tetrazolium test in chronic granulomatous disease. New Eng. J. Med., 278, 971.

BJöRKSTEN, B. AND SolHEIM, F. 1973. Oral contraceptives and the N.B.T. test. Lancet, 1, 830.

Charette, R. AND Komp, D. M. 1972. NBT test and incubation temperature. New Eng. J. Med., 287, 991.

Chretien, J. H. AND Garagusi, V. F. 1972. Corticosteroid effect on phagocytosis and NBT reduction by human polymorphonuclear neutrophils. J. reticuloendothel. Soc., 11, 358.

Farnes, P., Povar, M. L., Fieschko, J. AND Barker, B. E. 1972. N.B.T. tests in dog neutrophils. Lancet, $1,47$.

FeIGIN, R. D. 1971. NBT test in the diagnosis of febrile patients. New Eng. J. Med., 285, 347.

Feigin, R. D., Shackelford, P. G., Choi, S. C., Flake, K. K., Francklin, F. A. JR, AND EISENBERG, C. S. 1971. Nitroblue tetrazolium dye test as an aid in the differential diagnosis of febrile disorders. J. Pediat., 78, 230.

FreEMAN, R. AND KING, B. 1972a. N.B.T. test. Lancet, 2, 380.

FrREMAN, R. AND KING, B. 1972b. Technique for performance of the nitro-blue tetrazolium test. J. clin. Path., 25, 912.

Freeman, R., KING, B. AND KITE, P. 1973. Serial nitroblue tetrazolium tests in the management of infection. J. clin. Path., 26, 57.

GifFORD, R. H. AND MALAwISTA, S. E. 1972. The nitroblue tetrazolium reaction in human granulocytes adherent to a surface. Yale J. Biol. Med., 45, 119.

Gordon, A. M., Rowan, R. M., Brown, F. AND Carson, H. G. 1973. Routine application of the nitroblue tetrazolium test in the clinical laboratory. J. clin. Path., 26, 52.

Humbert, J. R., Marks, M. I., Hathaway, W. E. and Thoren, C. H. 1971. The histochemical nitroblue tetrazolium reduction test in the differential diagnosis of acute infections. Pediatrics, Springfield, 48, 259.

LANCET (LeADING ARTICLE). 1971. Nitroblue tetrazolium: a routine test ? 2, 909. 
MANDell, G. L. AND Fuller, L. F. 1972. Nitroblue tetrazolium dye test: a diagnostic aid in tuberculosis. Amer. Rev. resp. Dis., 105, 123.

Matula, G. and Paterson, P. Y. 1971a. Spontaneous in vitro reduction of nitroblue tetrazolium by neutrophils of adult patients with bacterial infection. New Eng.J. Med., $285,311$.

Matula, G. and Paterson, P. Y. $1971 b$. N.B.T. tests in a patient on steroids. Lancet, 1, 803.

Matula, G. and RaAs, M. 1973. Nitroblue tetrazolium dye test. Ann. intern. Med., 79, 758.

Miescher, P. A. AND LAMBERT, P. H. 1972. L'apport du test au NBT dans le diagnostic des états inflammatoires. Praxis, 61, 335.

Nydegger, U. E., Miescher, A., Anner, R. M., Creighton, D. W., Lambert, P. H. AND MIESCHER, P. A. 1973. Serum and cellular factor involvement in nitroblue tetrazolium (NBT) reduction by human neutrophils. Klin. Wschr, 51, 377.

Park, B. H. 1971. The use and limitations of the nitroblue tetrazolium test as a diagnostic aid. J. Pediat., 78, 376.

Park, B. H., Fikrig, S. M. AND Smithwick, E. M. 1968. Infection and nitroblue tetrazolium reduction by neutrophils. A diagnostic aid. Lancet, 2, 532.

PARK, B. H. AND GoOd, R. A. 1970. N.B.T. test stimulated. Lancet, 2, 616.

Pujol-Morx, M. N. 1973. Nitroblue-tetrazolium reducing capacity of neutrophils in diabetes. New Eng. J. Med., 289, 920.

Rubinstein, A. And Pelet, B. 1973. False-negative N.B.T. tests due to a transient malfunction of neutrophils. Lancet, 1, 382.

Segal, A. W. AND LeVI, A. J. 1973. The mechanism of the NBT (nitroblue tetrazolium) test. Clin. Sci., 44, 26P.

Sobel, J. D., Obedeanu, N., Blank, S., Levy, I., Valero, A. And Merzbach, D. 1973. The nitroblue tetrazolium test in the investigation of febrile patients. S. Afr. med. J., 47, 1407.

Štrukel, M. ANd Žemva, M. 1973. Modification of the N.B.T. test. Lancet, 1, 149.

TADMOR, B. AND AltmanN, G. 1971. The NBT test in patients with various infections. Harefuah, 83, 155.

Tan, C. V., Rosner, F. ANd Feldman, F. 1973. Nitroblue tetrazolium dye reduction in various hematologic disorders. N.Y. State J. Med., 73, 952.

Vaucher, A., Wyss, M., Thévoz, F., Knopfel, M. AND Miescher, P. A. 1970. La réduction du nitrobleu de tétrazolium par les granulocytes dans divers états cliniques. Schweiz. med. Wschr, 100, 2248.

Vega, G. de la, Freyre-Horta, R. and Benitez-Bibriesca, L. 1973. Plasma factor affecting the NBT reducing capacity of neutrophils. New Eng. J. Med., 289, 271.

Wenger, M. E. AND Bole, G. G. 1973. Nitroblue tetrazolium dye reduction by peripheral leukocytes from rheumatoid arthritis and systemic lupus erythematosus patients measured by a histochemical and spectrophotometric method. J. Lab. clin. Med., 82, 513. 